\title{
Multifaceted Bioinspiration for Improving the Shaft Resistance of Deep Foundations
}

\author{
Seyed Ali Aleali, Paola Bandini", Craig Michael Newtson \\ Center for Bio-mediated and Bio-inspired Geotechnics, Department of Civil Engineering, New Mexico State University, \\ Las Cruces, New Mexico 88003-8001, USA
}

\begin{abstract}
This paper describes the bioinspiration process to derive design concepts for new deep foundation systems that have greater axial capacity per unit volume of pile material compared to conventional deep foundations. The study led to bioinspired ideas that provide greater load capacity by increasing the pile shaft resistance. The bioinspiration approach used problem-solving strategies to define the problem and transfer strategies from biology to geotechnical engineering. The bioinspiration considered the load transfer mechanism of hydroskeletons and the anchorage of the earthworm, razor clam, kelp, and lateral roots of plants. The biostrategies that were transferred to the engineering domain included a flexible but incompressible core, passive behaviour against external loading, a longitudinally split shell that allows expansion for anchorage, and lateral root-type or setae-type anchoring elements. The concepts of three bioinspired deep foundation systems were proposed and described. The advantage of this approach was illustrated with two examples of the new laterally expansive pile in drained sand under axial compression. The finite element analysis of these examples showed that the new laterally expansive pile can provide considerably greater load capacity compared to a conventional cylindrical pile due to the increased lateral confining pressure developed along the expanded pile core.
\end{abstract}

Keywords: bioinspiration, expansion, anchorage, deep foundation, pile capacity, frictional resistance

Copyright $(\odot)$ The author(s) 2020.

\section{Introduction}

Identifying and studying behaviours and strategies found in organisms to learn from them and extract desirable ideas to solve problems or enhance solutions in geotechnical engineering is a relatively new subdiscipline within biogeotechnics ${ }^{[1]}$. Nature can be a mentor, a benchmark, and a model because human beings can learn from nature, measure correctness of their current solutions based on it, and take inspiration from $\mathrm{it}^{[2]}$. The end goal of learning from nature and biological organisms is often invention and creation. Having this common goal has led researchers to use different terms such as biomimetics, biomimicry, and bioinspiration with similar meaning ${ }^{[3]}$. In this paper, bioinspiration refers to the process of learning from one or more organisms or being inspired by them with the purpose of solving a problem or improving a process in another field. When successful, the outcome of bioinspiration is a solution to a problem or a more effective design.

Bioinspiration may start by studying, in detail, one or more selected organisms, describing their forms and behaviour, and then identifying potential applications of these observations (i.e., solution-based design methodology). Another approach to bioinspiration consists of describing the problem and searching for one or more biological analogues that can provide strategies to arrive at a new or improved solution to the target problem (i.e., problem-based design methodology). In the problem-driven process, it is important to use a systematic process for problem solving to avoid time consuming searches that may not yield desirable or useful results.

In most cases, there are noticeable differences between the way how biological species behave and how technical problems with analogous circumstances are solved applying conventional engineering methods ${ }^{[4]}$. Bioinspiration may lead to solutions or alternative better solutions compared to the current practice. For example, energy and material consumption in bioinspired solutions may be low comparted to conventional engineering methods $^{[5]}$. Other important features of an ideal bioinspired system may be simplicity, durability (working

\footnotetext{
*Corresponding author: Paola Bandini

E-mail: paola@nmsu.edu
} 
properly during a pre-defined life span), ease of control, and sustainability ${ }^{[6]}$.

TRIZ (an acronym for "Teoriya Resheniya Izobretatelskikh Zadatch" in Russian) is a framework for problem solving ${ }^{[7]}$ that includes these main strategies: defining the problem and the characteristics and functions of the desired solution or outcome; identifying the technical contradictions (i.e., desired improvement in one technical aspect of the solution is at the expense of another part of the solution getting worse) to achieve the desired function(s) based on available technology; and systematically selecting from a list of "inventive principles" of TRIZ ${ }^{[7]}$ the combination of the most desirable parameters (i.e., those that overcome the technical contradictions) that constitute the solution to the problem. The TRIZ framework can be useful to transfer a solution from one discipline to another ${ }^{[8]}$ and has been used in engineering design ${ }^{[5,9,10]}$. Transferring ideas from biology to engineering can be done at different levels, depending on the similarities between the technical problem and the selected biological model (i.e., when the characteristics of the technical problem are significantly different from those of the biological model, the analysis of the biological model should start at a fundamental knowledge level ${ }^{[11]}$.

The potential of bioinspiration for new designs in civil engineering was illustrated by $\mathrm{Hu}$ et al. describing the bioinspired designs used in several bridge projects ${ }^{[12]}$. Another example was an analytical study of the performance of trees from a structural engineering perspective only to transfer basic design concepts of these structural characteristics to simple moment frames under combined external loading conditions ${ }^{[13]}$. Bioinspiration has also been implemented to solve geotechnical engineering problems. Drawing inspiration from the earthworm, razor clam and other soil burrowing organisms, soil penetration devices are being developed as alternatives or enhancement to common subsurface exploration technologies like the Cone Penetration Test $(\mathrm{CPT})^{[14-16]}$. Several burrowing strategies of the razor clam were used to create a bioinspired device called RoboClam that digs into soil for engineering applications ${ }^{[17,18]}$. The mechanisms of burrowing of the razor clam in sand were also studied numerically using a discrete element method ${ }^{[16]}$. In the mathematical model, the relevant clam compo- nents were simplified using a cylinder with a conical tip to represent the body and foot, respectively. The radius of the cylindrical body could vary to simulate the frequent expansion and contraction of the clam body and shell during burrowing into soil ${ }^{[16]}$. Some aspects of ant-soil and root-soil interactions and plant physiology have also been used to derive ideas and identify areas of potential for the development or enhancement of methods and design in biogeotechnical engineering ${ }^{[19,20]}$.

This paper describes the process used to derive bioinspired solutions for a geotechnical engineering problem, particularly for the development of a deep foundation system. The goal of this study was to create a deep foundation with greater axial (downward) capacity per unit volume of pile material compared to conventional deep foundations. Structural loads from infrastructure like multi-story buildings, bridges and overpasses, transmission towers, signboards, and wind turbines are generally supported by deep foundations. The types of deep foundations most widely used in practice are driven piles and bored piles (also called drilled shafts). A component of the pile's axial capacity results from the resistance developed in the soil-pile contact region along the pile shaft when the axial loading is applied. This is called shaft or frictional capacity $\left(Q_{s}\right)$ and is the resultant of the unit frictional resistance $(f)$ over the pile shaft area $\left(A_{s}\right)$, so that $Q_{s}=\Sigma\left(f A_{\mathrm{s}}\right)$. For downward loading, the other component of the axial capacity is provided by the resistance of the bearing layer at the pile end $\left(Q_{p}\right)$ and is referred to as end-bearing capacity (also called tip or point capacity). The $Q_{s} / Q_{p}$ ratio depends on several factors such as site-specific soil or geological conditions, pile type and installation method, and relative axial displacement of the pile during service loading.

The focus of this paper is on the bioinspiration process to develop pile systems with greater axial capacity by enhancing the shaft resistance. The study used bioinspiration combined with, but not restricted to, some aspects of the TRIZ problem-solving framework that were particularly useful to define the problem, identify highly influential parameters such as the soil confining pressure, shear strength, type and state of the soil, and pile surface roughness, and finally identify the technical contradictions and obstacles. Anchorage strategies of the 
earthworm, razor clam, plant roots, and kelp as well as the advantages provided by hydrostatic skeletons were identified and considered. A combination of various biological strategies led to proposing concepts for three new deep foundation systems with enhanced shaft resistance. Two examples were modeled numerically to illustrate the potential of the new approach. Fabrication and installation costs and constructability are outside the scope of this paper.

\section{Problem description}

The research described in this paper is a bioinspired design process for deep foundations. The study adopted some elements of the TRIZ methodology for the problem definition. The initial step consisted of describing the target problem in detail including its desirable functions, properties or capabilities, environment, time-related characteristics or performance features, and scales and/or dimensions. In this study, the problem was defined as a single-pile system that efficiently provides greater axial (downward) load capacity from enhanced shaft resistance per unit volume of pile compared to conventional prismatic or cylindrical pile foundations. The shaft capacity per unit volume of pile installed into the ground is referred herein as the target function. The target function was defined per unit pile volume because the latter is often used as a basis of comparison encompassing cost of material fabrication, transportation, and installation. The problem was constrained to a geological environment in which a strong bearing layer or the bedrock is relatively deep so that deep foundations that rely primarily on end-bearing capacity to carry the structural loads would not be economically viable or practical. The site in which the pile system would be installed could consist of granular soils not susceptible to liquefaction. For these site conditions, the current practice would design piles that develop a considerable fraction or most of their axial capacity from shaft resistance.

At this stage, no specific scale or dimension of the problem was specified so that the bioinspired study could be addressed at the microscale and macroscale. A microscale study might investigate phenomena at the particle scale that involve the role of soil pore spaces, particle aggregates, and matric suction, or the effects of microbes on the shear strength of the soil. Examples of macroscale studies are the effects of size, shape, and method of construction and installation of the pile on the shear strength of the soil-pile contact surface. In terms of time-scale requirements of the solution, it is important that any gain in soil strength or shaft resistance be permanent (i.e., it should last the project design service life).

The description of the problem indicates that the bioinspired pile system will have greater axial (downward) load capacity by enhancing the shaft resistance. However, end-bearing capacity may also increase in the bioinspired solution even though this is not part of the defined problem. In practice and for a given site and geologic conditions as those of the problem, the need for increasing the pile axial capacity considerably would be achieved by increasing the pile length and/or the cross sectional area, and selecting a pile type and installation method that would cause either the minimum disturbance possible of the soil surrounding the pile if installed in saturated clayey soil or the greatest densification of the soil around the pile if installed in granular soil. Other factors may play a role in the selection of the pile type and installation method such as the susceptibility of adjacent structures to settlement and vibrations, project size, lateral loading, owner or agency preference, and availability and experience of pile installation contractors in the area ${ }^{[21]}$.

The shaft resistance increases with depth, but the increase rate is not necessarily linear. Based on pile load test data and numerical analysis, beyond a certain depth, the rate of increase of $f$ becomes slower. There is no general consensus on the most appropriate approach to account in design for the lesser rate of shaft resistance increase with depth ${ }^{[22]}$. This phenomenon has been attributed to limiting values of the soil friction angle and lateral earth pressure at greater depths ${ }^{[23]}$, which are main factors that contribute to the shaft resistance. Simplified guidelines often used in practice apply a limiting shaft resistance value so that $f$ increases linearly up to a certain depth and remains approximately constant thereafter ${ }^{[24]}$. Because the problem was described in terms of load capacity increase per unit volume of pile installed into the ground, achieving greater load capacity by making the pile longer and/or wider (i.e., increasing 
$A_{s}$ ) could be considered as a technical contradiction against the target function. In other words, enlarging $A_{s}$ to increase $Q_{s}$ would lead to greater pile volume and likely does not result in greater shaft capacity per unit pile volume. Other issues associated with increasing the length of driven piles are early refusal (i.e., pile ceases to penetrate the ground during driving before reaching the specified embedment depth) and greater required driving energy and cost.

The magnitude and nature of $f$ depend also on the shear strength of the pile-soil contact surface, which is a function of the pile surface roughness ${ }^{[25]}$, normal confining pressure from the surrounding soil ${ }^{[26,27]}$, soil density prior to pile installation ${ }^{[28]}$, soil type and shear strength $^{[21,29]}$, and soil particle angularity ${ }^{[30,31]}$. Other parameters may also affect the shaft resistance to a lesser degree. In granular soils, the effect of the soil-pile surface roughness on the surface's shear strength has an upper limit because increasing the soil-pile surface roughness could only enhance the surface friction up to the angle of internal friction of the surrounding soil ${ }^{[25]}$.

Some obstacles or difficulties may limit the ability to increase $f$. An example of an obstacle to increasing the unit shaft resistance is the lack of practical means to modify the soil particle angularity in the natural environment of this problem. Another obstacle would be the technical or physical difficulties and associated costs of accessing the soil around the pile to modify its properties after installation. Soil desaturation around the pile could lead to increasing $f$. However, the technical barriers and complexities involved in modifying and/or controlling the degree of saturation of the soil around the pile in the long term are also obstacles.

After evaluating the potential influential factors and considering the technical contradictions and obstacles, the lateral (or normal) confining pressure exerted by the ground against the pile shaft was identified as a factor with significant potential for increasing the unit shaft resistance. Thus, the problem was redefined according to this key factor. Fig. 1 illustrates this initial stage of the problem-solving process for increasing the unit shaft resistance of a pile by increasing the soil lateral confining pressure. The next steps aimed at finding one or more bioinspired strategies through which the increase in lateral confining pressure against the pile could be achieved.

\section{Bioinspiration}

A search for analogues and sources of bioinspiration identified some organisms as relevant and promising for improving the unit shaft resistance in the redefined problem. This section describes behaviors and strategies of the selected biological analogues, including the root anchorage systems, the hydrostatic skeleton of invertebrates and other animals, and the anchorage of the razor clam during burrowing.
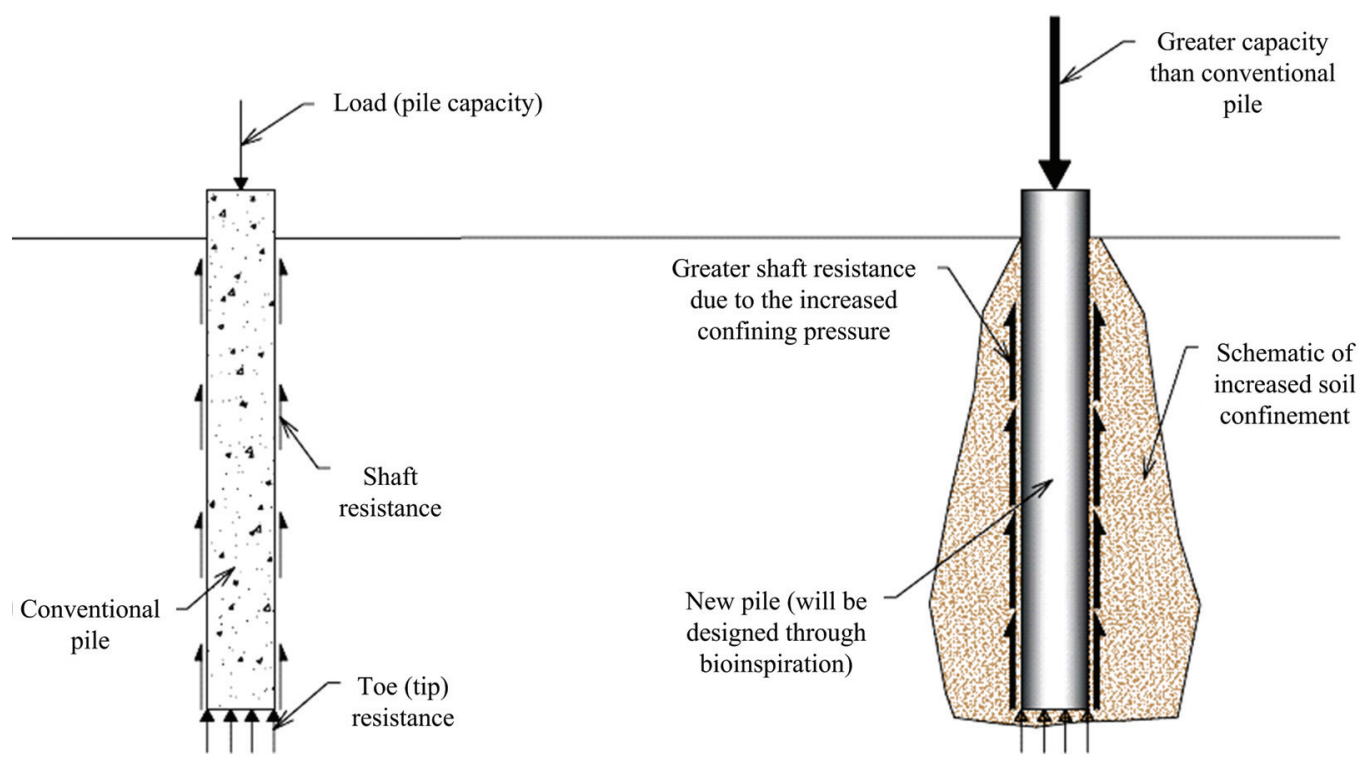

Fig. 1 Schematic description of the redefined problem. (a) Conventional pile; (b) new pile. 


\subsection{Bioinspiration 1: Root anchorage}

Biological species often exhibit flexibility (a form of passive behavior) when subjected to external forces or pressure to protect themselves, transfer the applied load to stronger parts of their body, or dissipate the applied load. Macroalgae of the order Laminariales (Phaeophyceae), often referred to as kelps, are found abundantly in shallow coastal or subtidal rocky habitats. To resist tidal waves and marine currents, Laminariales have a root-like tapered structure called holdfast at the bottom of their stem (Fig. 2a), whose main function is to attach firmly to the rock substrate like an anchor. Unlike roots, the holdfast does not absorb nutrients. The connection between the long, flexible stem, called stipe, and the holdfast is also flexible to reduce the impact of hydrodynamic forces. The flexibility of the stipe in all directions helps reduce the shear stress and prevent detachment under the wave action ${ }^{[32]}$. Water flow would induce considerable shear stress on the stem if it were rigid (Fig. 2b); instead, the stipe bends so that the water flow induces a drag force (Fig. 2c). The flexible stipe is much stronger in tension than in shear.

A similar strategy is also used by lateral roots of trees and plants. In soil profiles composed of alternated layers of relatively weak and strong zones, tree roots (Fig. 3a) may not penetrate the strong soil; instead, lateral roots would grow into the weaker soil, which offers less resistance. The growth path is diverted when roots encounter an obstacle in their path ${ }^{[35]}$. When growing in weaker zones bounded above and below by layers of stronger soil, the roots can also resist greater pullout forces. As the root grows in length and diameter, the weaker soil around it becomes denser without disturbing the adjacent stronger zones. This contributes to increasing the confining pressure in the normal direction to the root surface, as illustrated by arrows in Fig. 3b. Moreover, lateral roots are flexible so that they can bend and move to prevent breaking in shear. The main

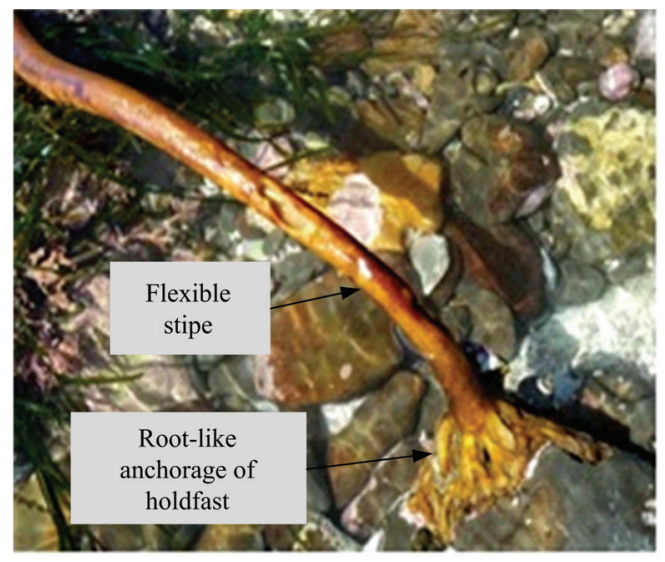

(a)

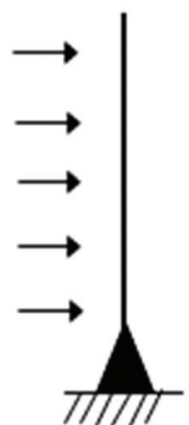

(b)

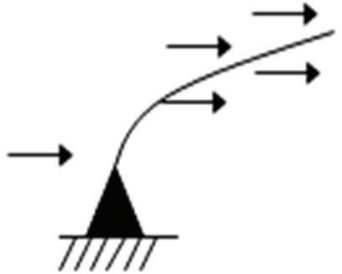

(c)

Fig. 2 Anchorage behavior of Laminariale algae (kelp). (a) Kelp anchored to a rock ${ }^{[33]}$; (b) schematic view of an idealised kelp with rigid stipe; (c) schematic view of a kelp with flexible stipe.

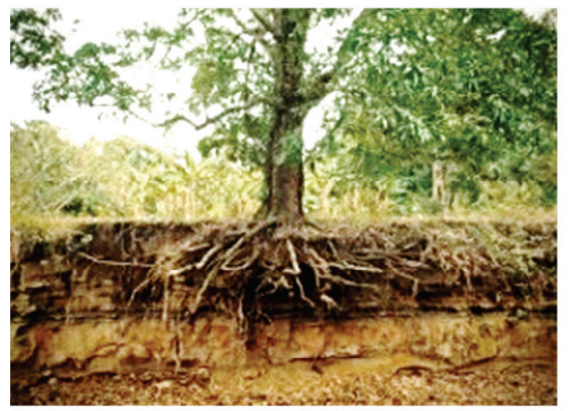

(a)

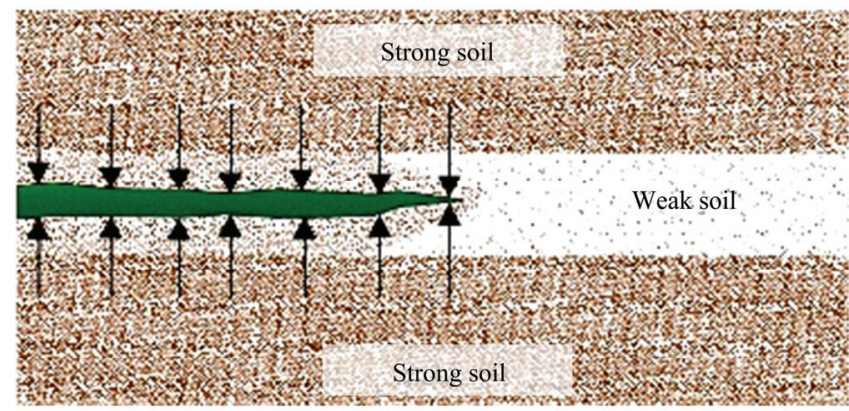

(b)

Fig. 3 Tree lateral root anchorage behaviour. (a) Cross section of a tree root in a soil profile ${ }^{[34]}$; (b) confinement of a lateral root by contiguous stronger soil zones. 
inspiration from the kelp and lateral root anchorage examples is the use of passive behavior to resist or accommodate to different types of external loading.

\subsection{Bioinspiration 2: Hydrostatic structure}

Many diverse organisms use hydrostatic skeletons for support, movement, muscle contraction and antagonism functions ${ }^{[32]}$, transmission of external forces, shock absorption or damping, and anchorage. The hydrostatic skeleton (often referred to as hydroskeleton) consists of a liquid that is fully enclosed by a layer of connective tissue fibers that control shape changes ${ }^{[36]}$. The volume of the hydrostatic skeleton remains constant because the fluid is relatively incompressible (i.e., it has high bulk modulus) and the internal volume is maintained nearly constant. Another interesting characteristic of hydrostatic skeletons of many animals is that their shape is approximately cylindrical with muscles that control the diameter and length of the structure ${ }^{[37]}$. The hydrostatic skeletons of several animals were used as sources of information and ideas in this bioinspiration study. For instance, foot pads of mammals (Fig. 4a) have a hydrostatic structure that works as a fluid-filled cushion and a viscoelastic damper against impacts on bones ${ }^{[32,39,40]}$. Fig. 4 illustrates schematically the damper-like mechanism through which an impact on a cat foot is dissipated to protect the foot bone from the impact. The impact on the foot immediately becomes internal hydrostatic pressure that is distributed throughout the fluid enclosed in the compartment of the foot pad. Then, the hydrostatic pressure is transferred to the wall of the compartment where it becomes tensile stress along the wall. That mechanism minimizes the effect of the impact on the bone of the cat foot.

The main body cavity of invertebrate organisms, such as annelids, is called coelom (Fig. 5a). The pressure of the fluid inside the coelom exerts longitudinal and circumferential stresses on the body like in a pressurized thin-walled cylinder (Fig. 5b) ${ }^{[36,41]}$. This type of structure allows transfer of external loads that eventually become tensile stresses in the muscle tissues of the body. In annelids, the coelom is filled with coelomic fluid and is divided into segments by muscular septa. The coelomic fluid in each segment is prevented from moving to other coelomic compartments during motion so that each segment operates independently. The various sets of muscle fibers can contract and relax as needed to change the shape and/or diameter of the individual coelom segments ${ }^{[36,41]}$. Locomotion of earthworms is managed by antagonistic pairs of longitudinal and circular muscles in the segments (Fig. 5c). When the earthworm wants to burrow forward into the soil, a series of circular muscles in the anterior segments contract so that the anterior parts become like a thin, tightened thrust. To create the anchorage that prevents the earthworm from moving backward during burrowing in soil, the posterior segments perform two actions simultaneously. First, the longitudinal muscles contract and the corresponding circular muscles relax to make the posterior segments expand radially; this expansion generates normal pressure against the surrounding soil that increases the surface friction between this part of the earthworm body and the soil (Fig. 5c). Secondly, the protractor muscles extend out small bristles, called setae, into the surrounding soil (Fig. 5d) that contribute to anchoring the expanded part of the earthworm body. The peristaltic movement includes elongation, shortening, expansion, and contraction of the body.

\subsection{Bioinspiration 3: Razor clam}

The razor clam (Ensis directus) is a narrow, elongated marine bivalve mollusk that can dig quickly into
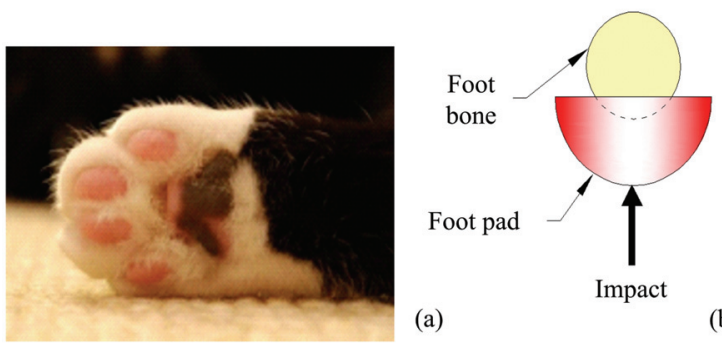

(b)

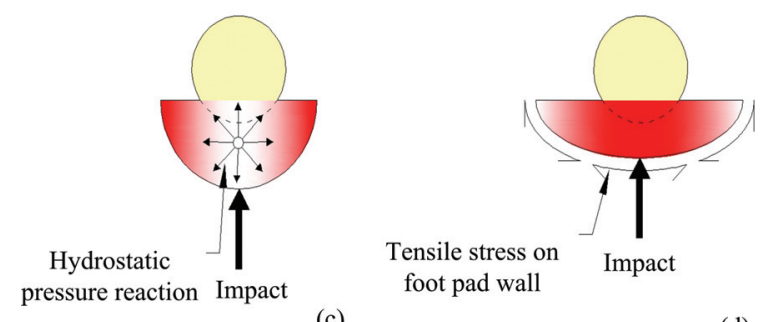

(d)

Fig. 4 Hydroskeleton structure in foot pads of cats. (a) A view of the foot $\operatorname{pad}^{[38]}$; (b) an impact applied on the foot pad; (c) hydrostatic pressure generated in the fluid inside the foot pad; (d) shape change and tensile stress on the wall of the foot pad due to the hydrostatic pressure. 


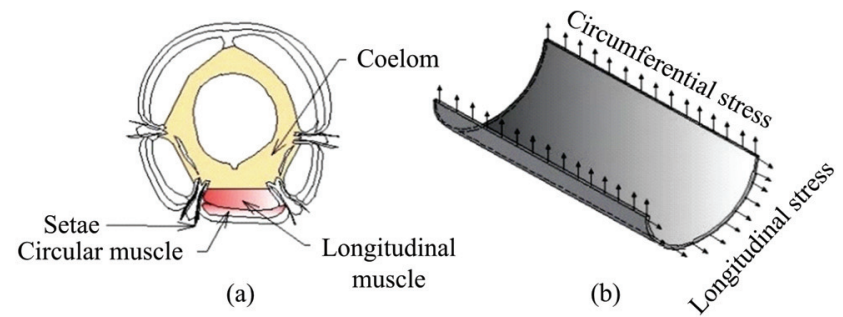

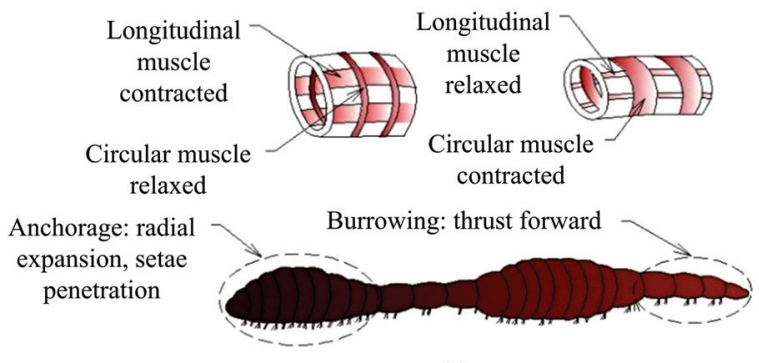

(c)

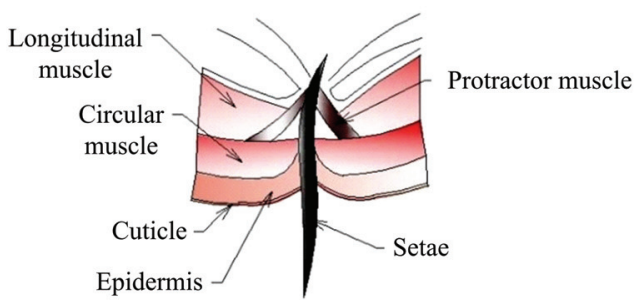

(d)

Fig. 5 Load transmission mechanism and anchorage behavior in an earthworm. (a) Transversal cross section of the fluid-filled cavity of the earthworm (coelom); (b) longitudinal and circumferential stresses on a section of a pressurized thin-walled cylinder; (c) burrowing and anchorage: Antagonistic actions of circular and longitudinal muscles; (d) details of setae anchorage.

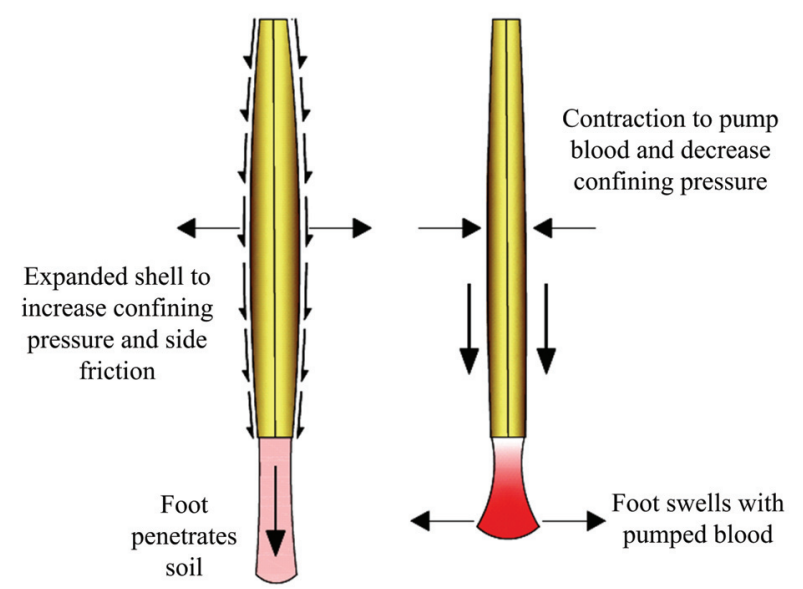

(a)

(b)

Fig. 6 Anchorage behavior of the razor clam. (a) The foot penetrates the sand while the body is anchored; (b) the shell closes to advance the body.

the sand and mud by expanding and contracting the body. The razor clam starts burrowing by pushing the foot into sand; blood is pumped to the foot and the swollen foot serves as anchor while the clam drags the rest of the body forward into the sand. While the body moves forward, the shell remains closed to decrease the confining pressure and friction between the sand and the shell surface. Once the body has advanced into the sand, blood is pumped back to the body to expand the valves laterally. The lateral expansion of the shell increases the soil confinement and side friction to provide anchorage while the thinner foot penetrates further into the sand (Fig. 6a). The blood is pumped again from the body to the foot. The fast contraction of the shell draws water towards the body disturbing the sand around it. This process locally liquefies the sand surrounding the shell and reduces the shear strength of the soil, so the razor clam needs less energy to move the foot forward into the sand ${ }^{[42]}$. Some of the burrowing strategies of the razor clam have similarities with those used by the earthworm; a major difference is the hard shell of the razor clam. The hard shell provides outer strength to the soft body but does not prevent the lateral expansion because the razor clam has a bivalve (or two-part) shell.

\section{Results}

The results are presented in two parts. The bioinspired design concepts of the new deep foundation systems are described first. The second part provides a numerical modeling example of the laterally expansive pile compared to a conventional cylindrical pile in terms of lateral confining pressure and load capacity.

\subsection{Bioinspired design results - Preliminary con- cepts}

The following strategies were selected for devel- 
oping one or more pile systems with greater shaft capacity per unit pile volume:

Strategy 1: Use a flexible but nearly incompressible inner core along with a hard shell, instead of using an entirely rigid system.

Strategy 2: Use a longitudinally split hard shell that provides a lateral or radial degree of freedom, instead of a cylindrical steel pipe pile.

Strategy 3: Incorporate lateral root-type or setae-type anchor elements along the pile length, instead of relatively smooth pile surface.

Table 1 links the biological analogues to the desirable biostrategies. To complete the bioinspiration process, the identified biological strategies were incorporated into one or more problem solutions. The concepts of three bioinspired pile foundations are proposed based on the selected biostrategies and described in the following subsections.

\subsubsection{Bioinspired system 1: BREP}

The first system consists of a longitudinally split steel pipe with a nearly incompressible core and was named Bioinspired Radially Expansive Pile (BREP). The split pipe is the two-part shell of the system, inspired by the bivalve shell of the razor clam. Using two half pipes instead of a pipe allows lateral expansion. Fig. 7 illustrates the BREP components and two installation stages. The split steel pipe is driven into the ground; a driving cap is used to prevent pipe damage during installation and movement of shell halves. A driving shoe facilitates driving. The lower portion of the two-part shell is filled with a flexible but nearly incompressible material, such as compressed recycled rubber, polypropylene, dense granular soil, a fluid confined inside a chamber or membrane, or any other material with these characteristics (Fig. 7). The remaining upper part of the shell (above the compressed core) is filled with concrete and steel reinforcement as needed and topped with the pile cap. Inspired by the mechanism of hydroskeletons, the nearly incompressible core is loaded in compression along the vertical axis of the pile to expand it radially. The core is compressed until achieving the designed shell lateral expansion (Fig. 7b) that causes the desired increase in passive earth pressure in the surrounding soil. The increase in lateral earth pressure will lead to a substantial increase in shaft resistance of the pile. The compression of the core may be accomplished using tension rods or cables that connect the split shell with the top slab or other mechanisms. From this point of the installation process, the compression of the core remains locked. The BREP concept can also be implemented in soil anchors.

\subsubsection{Bioinspired system 2: BSAP}

The second design concept was inspired by a combination of anchorage mechanisms of the earthworm and razor clam. It takes advantage of three simple strategies of these biological analogues. First, like the bivalve shell of the razor clam, the pile has a two-arc steel shell to allow changes in diameter once the pile is in the ground. Second, a series of mechanical expansion devices (e.g., scissor jacks welded to a centre rod), housed inside the pile shell, are used to push the two

Table 1 Mapping of biological analogues and selected biostrategies

\begin{tabular}{ccccc}
\hline \multirow{2}{*}{$\begin{array}{c}\text { Biological } \\
\text { analogues }\end{array}$} & Biostrategies & \multicolumn{3}{c}{ Bioinspired systems } \\
\cline { 3 - 5 } $\begin{array}{c}\text { Earthworm, } \\
\text { razor clam }\end{array}$ & Lateral expansion for anchorage & $\checkmark$ & $\checkmark$ & $\checkmark$ \\
Razor clam & $\begin{array}{c}\text { Longitudinally split hard (bivalve) } \\
\text { shell that can move laterally }\end{array}$ & $\checkmark$ & $\checkmark$ & $\checkmark$ \\
$\begin{array}{c}\text { Hydrostatic } \\
\text { skeletons }\end{array}$ & $\begin{array}{c}\text { Flexible, incompressible body that } \\
\text { expands laterally for anchorage }\end{array}$ & $\checkmark$ & & \\
Setae & $\begin{array}{c}\text { Bristles penetrate in the soil to } \\
\text { anchor expanding body }\end{array}$ & & $\checkmark$ & $\checkmark$ \\
Kelp, & $\begin{array}{c}\text { Passive behavior to resist shear and } \\
\text { tensile forces }\end{array}$ & & & $\checkmark$ \\
lateral roots & $\quad$ & & & \\
\hline
\end{tabular}

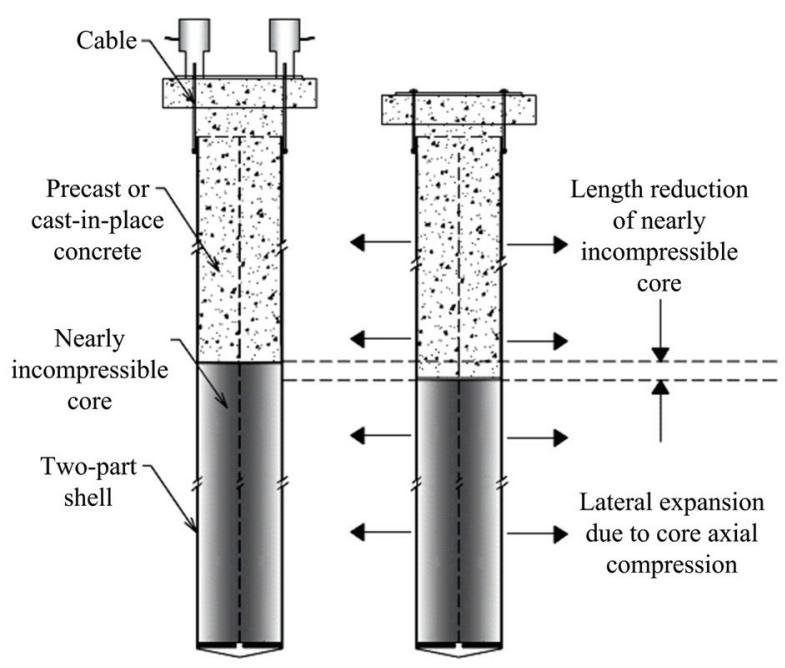

(a)

(b)

Fig. 7 Bioinspired Radially Expansive Pile (BREP). (a) Before expansion; (b) after expansion. 


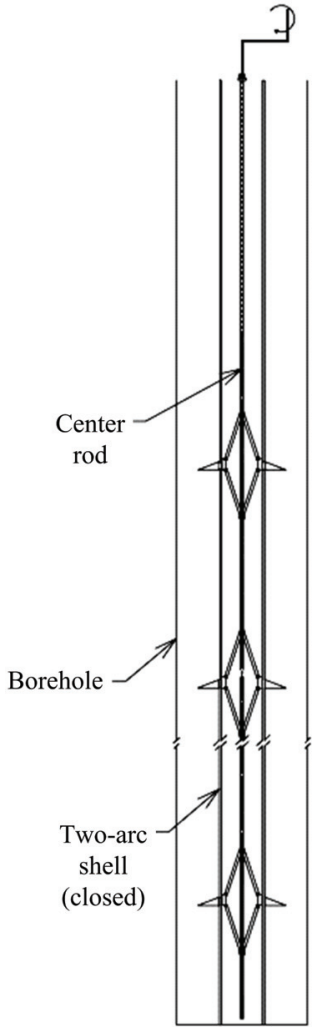

(a)
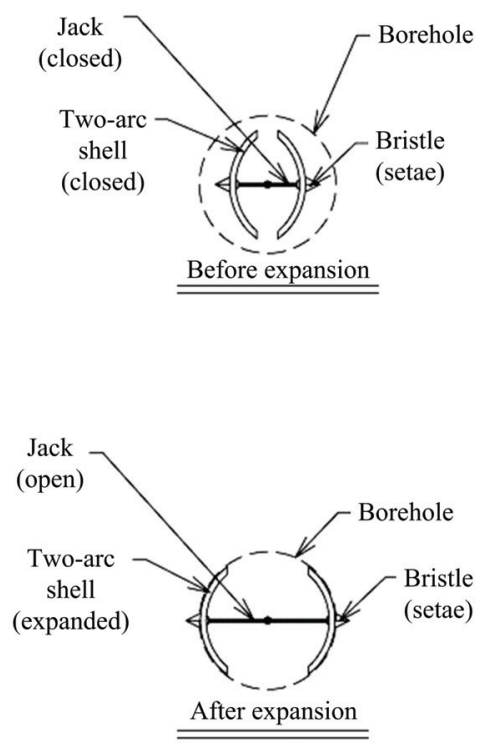

(b)

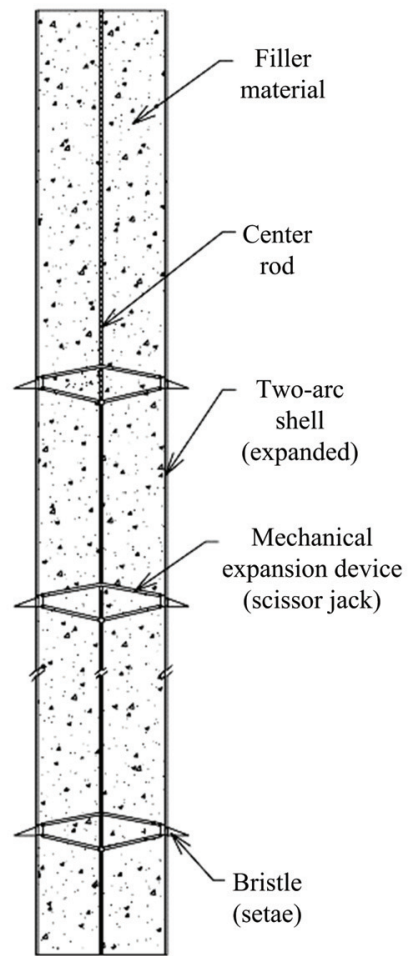

(c)

Fig. 8 Bioinspired Setae Anchored Pile (BSAP). (a) BSAP lowered down into borehole whilst the jacks are closed; (b) cross sections of the pile before and after expansion; (c) expanded BSAP with filler material.

parts of the steel shell outward against the soil. The lateral expansion of the steel shell increases the soil lateral confining pressure similarly to the radial expansion of the earthworm and razor clam to anchor one part of their body while the other part advances into the soil. Third, a series of steel bristles welded on the outer surface of the pile shell penetrate the soil as the shell expands, like the tiny setae of the earthworm that help anchor the body while burrowing.

This concept was named Bioinspired Setae Anchored Pile (BSAP) and can be implemented in bored piles and soil anchor systems. Fig. 8 illustrates the BSAP components and main stages of installation. Once the borehole has been opened using conventional drilling methods to a depth equal to the designed pile length, the shell-scissor jack expansion mechanism assembly is lowered into the borehole with the jacks fully closed (Fig. 8a). After the assembly is seated, the jacks are opened by a mechanism controlled from the ground surface. As the jacks push the shell parts outward against the soil, the lateral earth pressure on the two-arc shell increases. The passive earth pressure against the shell will provide greater shaft resistance to the pile. Opening the jacks also inserts the bristles through openings in the shell into the surrounding soil to provide additional anchorage (Fig. 8b). When the jacks are opened to the desired level, the space inside the shell can be filled with concrete (Fig. 8c) and topped with the pile cap. Additional steel rebars may be added to the assembly as needed for the structural design.

\subsubsection{Bioinspired system 3: BRAP}

The third design concept is called Bioinspired Root Anchored Pile (BRAP) and is a variation of the BSAP idea that incorporates inspiration from the anchorage approach of the Laminariales and lateral roots. The BRAP is installed as a bored pile and consists of a two-arc steel shell, inspired by the bivalve shell of the razor clam. When the borehole is opened to the designed pile length, the shell is lowered into the borehole. The 


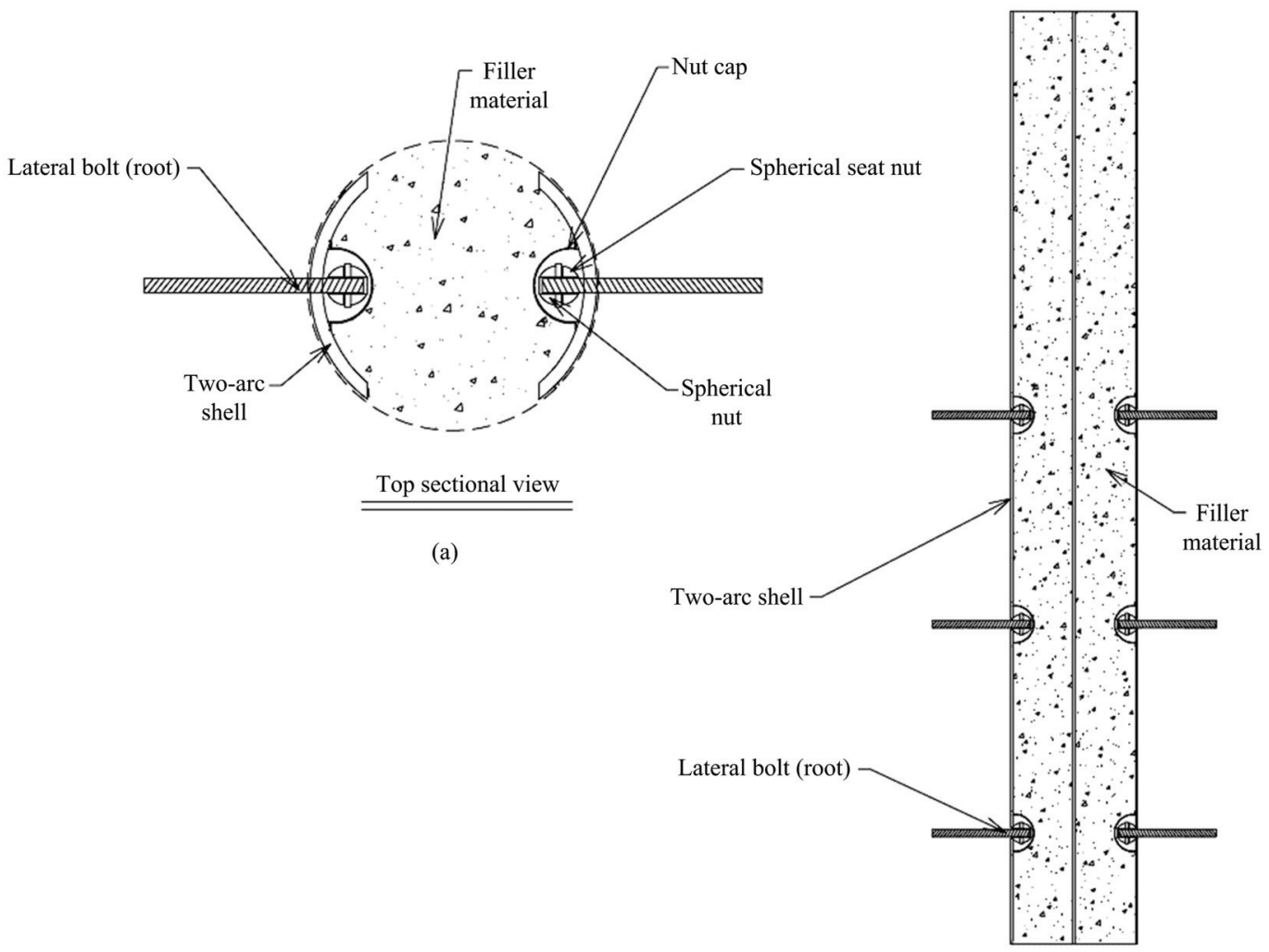

(b)

Fig. 9 Bioinspired Root Anchored Pile (BRAP). (a) Cross section view of the pile; (b) details of the pile on side section view.

two-arc shell has a series of small holes so that bolts can be installed through these holes into the soil (Fig. 9). The bolt installation needs to be done from the shell interior. As the bolts are screwed laterally into the ground, the shell is tightened and pushed toward the soil so that the earth pressure on the pile increases.

Like in the anchorage of lateral roots of plants, downward or upward forces on the pile cause the bolts to slightly rotate up or down, respectively, to mobilize the surrounding soil and provide resistance against the axial loading. The bolts do not need to have a large cross-sectional area to provide shear resistance. Instead, the hinge-type connection with a spherical nut at the interior end of the anchor bolt allows the bolts to rotate partially and mobilize their tensile strength (inspired by the anchorage mechanisms of the kelp) (Fig. 9a). The spherical nuts are protected by nut caps welded to the shell from the inside. After the shell and anchor bolts are installed, the shell inner space can be filled with concrete and steel reinforcement as needed for the structural design (Fig. 9b) and topped with the pile cap. Features of this pile system could be used as enhancements to the conventional large-diameter drilled shafts. Although using lateral anchor bolts can increase the pile shaft resistance, the feasibility of bolt installation with access restrictions inside the borehole might be controversial.

\subsection{Numerical modeling results}

Two numerical modeling examples of the laterally expansive pile subjected to axial compressive loading are described to illustrate the potential advantage of the bioinspired concept. The numerical analysis was performed using the Finite Element (FE) software ABAQUS $^{\circledR} 2017^{[43]}$. The examples compare laterally expansive piles with features similar to BREP to conventional cylindrical piles with the same dimensions in terms of the lateral confining pressure developed along the pile shaft and the ultimate load capacity. At this stage, the main purpose of this analysis is to observe the effect of the lateral expansion on the pile capacity. Lateral expansion is a commonality among the three pile systems. In addition, BSAP and BRAP include other ele- 
ments, such as steel bristles and lateral bolts, that penetrate the ground for providing additional shaft resistance. Thus, any improvement in load capacity shown by the FE results for the numerical model of BREP can be considered a lower bound for the other two systems.

The expansive piles comprise a two-part, cylindrical steel shell and a nearly incompressible core. The conventional piles are close-ended steel pipe piles. Table 2 shows the pile dimensions for the two examples. The steel of the piles and the nearly incompressible core are considered linear elastic. The Young's modulus and Poison's ratio are $210 \mathrm{GPa}$ and 0.3 for the steel and $0.1 \mathrm{GPa}$ and 0.48 for the nearly incompressible core, respectively. The piles are modeled in dry sand that has the properties of Erksak 330/0.7 sand (Silica sand with trace of silt and specific gravity of 2.66$)^{[44,45]}$. The two problems are modeled for loose, medium dense, and very dense sands with dry unit weight of $14.9 \mathrm{kN} \cdot \mathrm{m}^{-3}$, $15.9 \mathrm{kN} \cdot \mathrm{m}^{-3}$, and $17.0 \mathrm{kN} \cdot \mathrm{m}^{-3}$, respectively. The values of the friction angle of the pile-sand contact surface $\left(\delta^{\prime}\right)$ are assumed to be $20^{\circ}, 25^{\circ}$, and $35^{\circ}$ for loose, medium dense, and very dense sands, respectively, which are consistent with values recommended in the literature $^{[21,24]}$. The initial lateral earth pressure coefficient $\left(K_{\mathrm{o}}\right)$ used in the FE analysis is 0.9 which is in the expected range for driven displacement piles ${ }^{[21]}$. The mechanical behaviour of the sand is described by a unified critical state constitutive model referred to as CASM (Clay and Sand Model $)^{[46]}$. The material parameters used in the CASM model for this analysis are: Compression index, $\lambda$ $=0.0135$; specific volume at mean normal stress of 1 $\mathrm{kPa}, \Gamma=1.8167$; Poisson's ratio, $v=0.3$; reloading index, $\kappa=0.005$; slope of the critical state line, $M=1.2$; initial state parameter, $\xi_{R}=0.075$; and stress state coefficient, $n$ $=4.0^{[46]}$.

The FE results indicate that the pile expansion can lead to a significant increase in the lateral confining pressure along the expanded section of the pile compared to the conventional cylindrical piles. Fig. 10 shows the improvement in lateral confining pressure for the laterally expansive pile of Example 1 in loose, medium dense, and very dense sands at the end of expansion (before applying the structural load) as well as after axial loading when the pile vertical displacement $\left(\delta_{z}\right)$ is $25 \mathrm{~mm}$ (which can be considered as a serviceability
Table 2 Dimensions of the two laterally expansive pile examples

\begin{tabular}{cccccc}
\hline Example No. & $\begin{array}{c}\text { Pile length Pile diameter Shell thickness } \\
(\mathrm{m})\end{array}$ & $(\mathrm{m})$ & $\begin{array}{c}\text { Core } \\
(\mathrm{mm})\end{array}$ & $\begin{array}{c}\text { Core to pile } \\
\text { length }(\mathrm{m})\end{array}$ & \begin{tabular}{c} 
length ratio \\
\hline 1
\end{tabular} \\
\hline 10 & 0.3 & 8 & 6 & 0.60 \\
2 & 15 & 0.4 & 10 & 10 & 0.67 \\
\hline
\end{tabular}

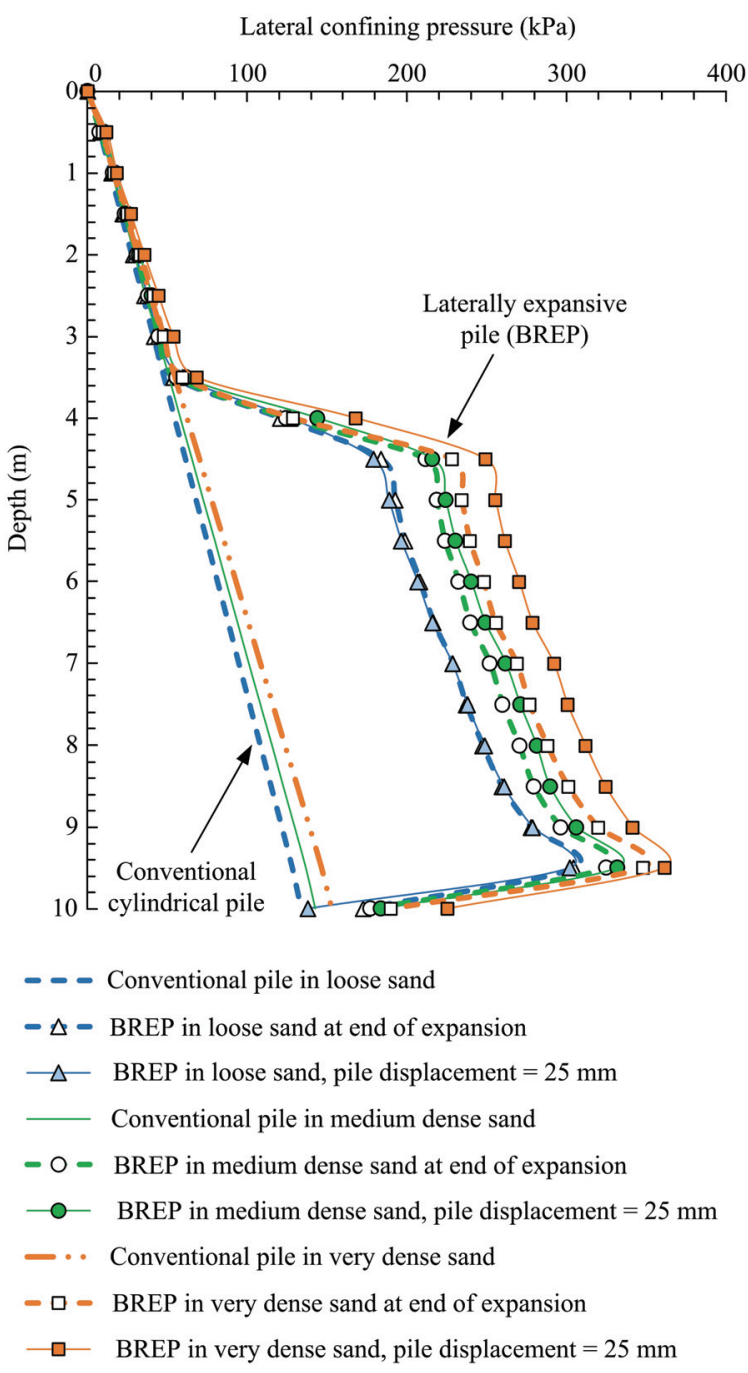

Fig. 10 Confining pressure on the laterally expansive pile (BREP) and conventional cylindrical pile of Example 1. Pile dimensions: $D=30 \mathrm{~cm}, L=10 \mathrm{~m}$.

limit). The improvement in the lateral confining pressure at the end of pile expansion is maintained after pile loading.

A parameter called herein unit confining force $\left(F_{c}\right)$, defined as the area within the lateral confining pressure curve, is introduced to quantify this enhancement. Table 3 shows the calculated $F_{c}$ values for the laterally expansive pile and the conventional pile of Example 1. For a given initial sand density, $F_{c}$ of the laterally expansive 
Table 3 Summary of FE modeling results for Example 1. Pile dimensions: $D=30 \mathrm{~cm}, L=10 \mathrm{~m}$.

\begin{tabular}{|c|c|c|c|c|c|c|}
\hline \multirow{3}{*}{ Sand type } & \multicolumn{4}{|c|}{$F_{c}\left(\mathrm{kN} \cdot \mathrm{m}^{-1}\right)$} & \multicolumn{2}{|c|}{$Q_{u}(\mathrm{kN})$} \\
\hline & \multirow{2}{*}{$\begin{array}{l}\text { Conventional } \\
\text { cylindrical pile }\end{array}$} & \multicolumn{3}{|c|}{ Laterally expansive pile } & \multirow{2}{*}{$\begin{array}{l}\text { Conventional } \\
\text { cylindrical pile }\end{array}$} & \multirow{2}{*}{$\begin{array}{c}\text { Laterally } \\
\text { expansive } \\
\text { pile }\end{array}$} \\
\hline & & $\begin{array}{l}\text { At end of } \\
\text { expansion }\end{array}$ & $\begin{array}{l}\text { At } \delta_{z}= \\
25 \mathrm{~mm}\end{array}$ & $\begin{array}{l}\text { At } \delta_{z}= \\
50 \mathrm{~mm}\end{array}$ & & \\
\hline Loose & 678 & 1484 & 1480 & 1469 & 310 & 650 \\
\hline $\begin{array}{c}\text { Medium } \\
\text { dense }\end{array}$ & 723 & 1620 & 1688 & 1682 & 400 & 975 \\
\hline $\begin{array}{l}\text { Very } \\
\text { dense }\end{array}$ & 776 & 1732 & 1893 & 1921 & 610 & 1470 \\
\hline
\end{tabular}

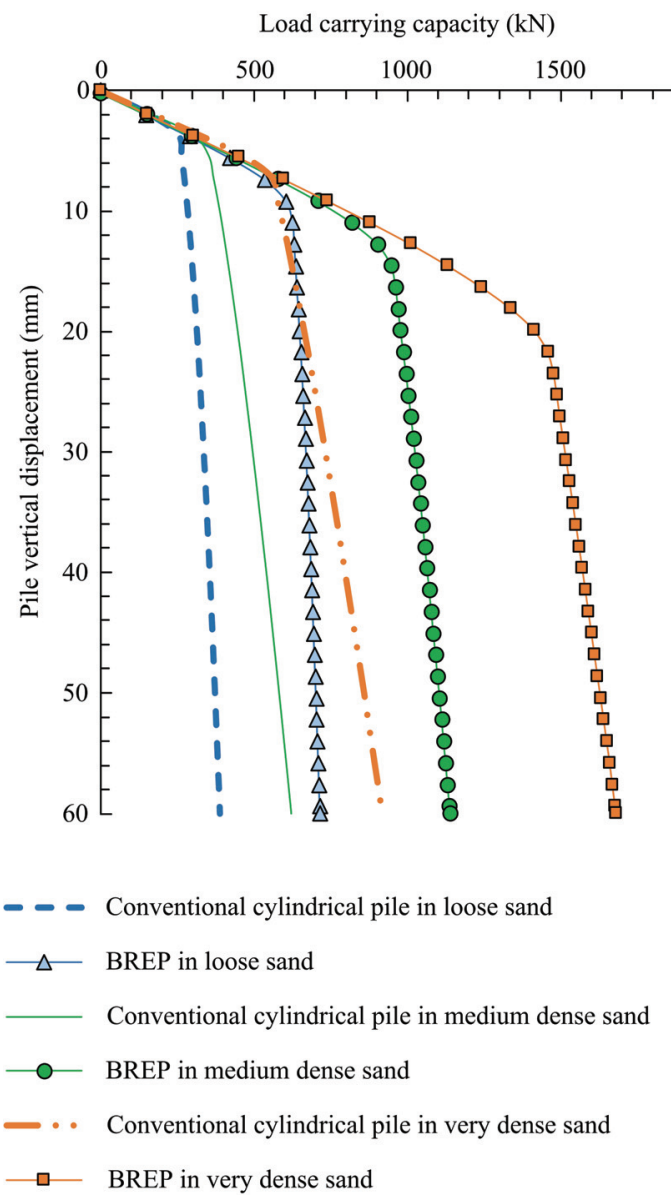

Fig. 11 Load-settlement curves for the laterally expansive pile (BREP) and conventional cylindrical pile of Example 1. Pile dimensions: $D=30 \mathrm{~cm}, L=10 \mathrm{~m}$.

pile at the end of expansion is more than twice $F_{c}$ of the conventional pile. The comparison of $F_{c}$ at $\delta_{z}=25 \mathrm{~mm}$ and $\delta_{z}=50 \mathrm{~mm}$ (twice the serviceability limit) also shows that the improvement is maintained during pile axial loading; however, there was a slight decrease of $F_{c}$ in loose sand at those two stages. The greatest increase in lateral confining pressure occurs along the expanded core, which in Example 1 is located in the lowest $6 \mathrm{~m}$ of

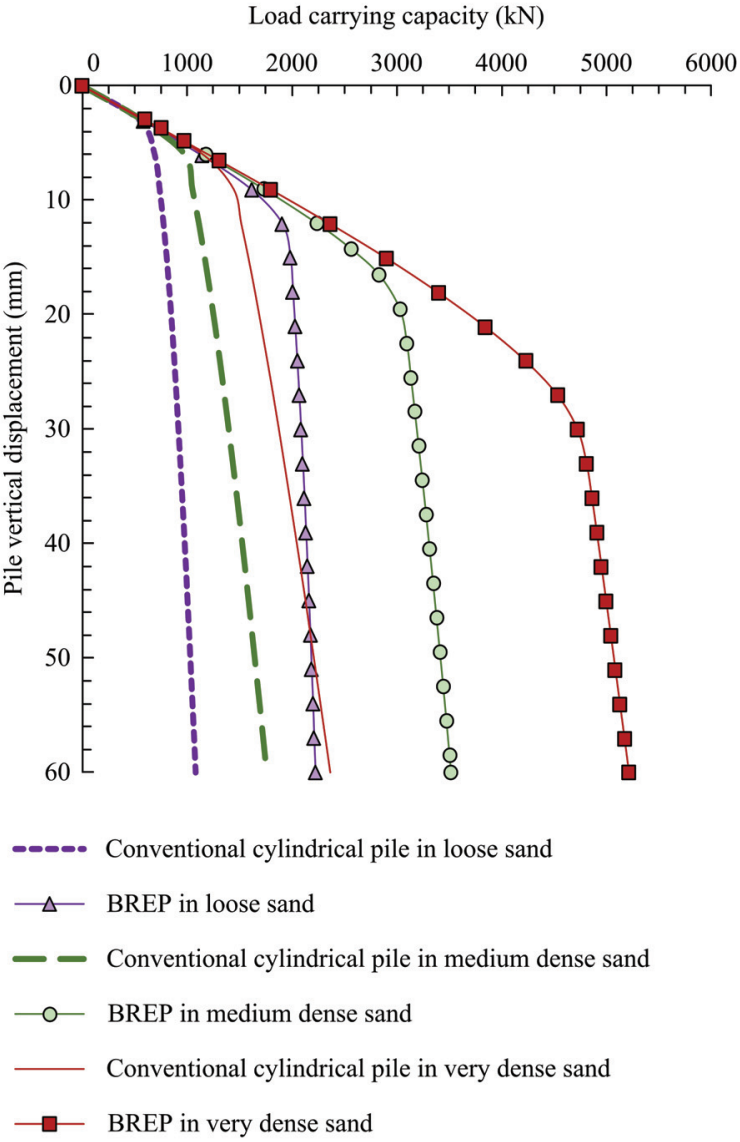

Fig. 12 Load-settlement curves for the laterally expansive pile (BREP) and conventional cylindrical pile of Example 2. Pile dimensions: $D=40 \mathrm{~cm}, L=15 \mathrm{~m}$.

the laterally expansive pile.

Fig. 11 compares the load-settlement curves of the laterally expansive pile and the conventional cylindrical pile of Example 1 obtained from the FE analysis. There is a remarkable increase in downward capacity in the laterally expansive pile in all three sand densities. The ultimate load (i.e., $Q_{u}=Q_{s}+Q_{p}$ ) of the laterally expansive pile and the conventional pile determined by the double tangent method are shown in Table 3. In Example $1, Q_{u}$ of the laterally expansive pile in loose sand is 2.1 times greater than $Q_{u}$ of the conventional cylindrical pile and in medium dense and very dense sands is 2.4 times greater than $Q_{u}$ of the conventional cylindrical pile. Load-settlement curves from the FE analysis of Example 2 are provided in Fig. 12. These results are consistent with those from Example 1. The $Q_{u}$ of the laterally expansive pile of Example 2 is $2020 \mathrm{kN}$ compared to $820 \mathrm{kN}$ for the conventional pile in loose sand, $3100 \mathrm{kN}$ 
compared to $1170 \mathrm{kN}$ for the conventional pile in medium dense sand, and $4700 \mathrm{kN}$ compared to $1680 \mathrm{kN}$ for the conventional pile in very dense sand.

\section{Discussion}

\subsection{Bioinspiration process}

A step-by-step bioinspiration study was performed to generate design ideas for new deep foundations with greater load carrying capacity, particularly greater shaft resistance, compared to conventional cylindrical driven or bored piles. Adopting some strategies from the TRIZ methodology during the problem-definition stage of the bioinspiration process was helpful because it provided a methodical perspective that facilitated arriving at more efficient and suitable solutions.

This study benefited from various biological analogues. During the bioinspiration process, it was learned that it is not necessary to focus on a single biological analogue and may be advantageous to consider a variety of biological strategies that can help find the best solution(s) possible. It was also learned that the analogue's behaviour gives one or more ideas to find the solution, which is not necessarily the final solution. The bioinspiration process identified and considered the load transfer mechanism of hydroskeletons and the anchorage strategies of biological analogues including the earthworm, razor clam, kelp, and lateral roots of plants. The passive behaviour against external loads was identified in some of these biological analogues. The biological strategies were transferred to the engineering domain and incorporated into the proposed design concepts: a flexible but incompressible core, longitudinally split shell, and lateral root-type or setae-type anchoring elements (Table 1).

\subsection{New deep foundation design concepts}

This study introduced the concepts of three bioinspired deep foundation systems. BREP is a driven pile that takes advantage of some anchorage strategies of the earthworm and razor clam and load transfer in hydroskeletons by using a flexible but nearly incompressible core and a longitudinally split, two-part steel pipe. Axial compression of the core pushes laterally the pipe parts against the surrounding soil to increase the confining pressure and, in turn, increase the pile shaft resistance. BSAP also takes advantage of the anchorage strategies of the earthworm and razor clam and consists of a two-arc steel shell, scissor-type jacks, and bristles. Opening the jacks pushes the shell laterally and penetrates the bristles into the surrounding soil. These two features have the potential to significantly improve the shaft capacity of the pile. BRAP takes advantage of anchorage strategies of the razor clam, Laminariales (kelp), and lateral roots of plants by using a two-arc steel shell and lateral anchor bolts with hinge-type connection. The shell expansion and the lateral bolts embedded into the ground contribute to the shaft capacity. Rotation of the hinge-type connection helps mobilize the tensile strength of the bolts, requiring bolts of smaller diameter compared to a rigid connection because only a small portion of the load is carried in shear. Compared to the other two bioinspired systems, BRAP is probably the least practical solution because of the difficulties of bolt installation inside the borehole. For the three proposed systems, once the pile expansion has been completed and locked, a pile cap is installed to connect the pile to the column as in conventional deep foundations.

The FE modelling examples showed that the pile lateral expansion leads to significant increase in the lateral confining pressure and ultimate load capacity compared to conventional cylindrical piles. At this stage, the main purpose of this FE analysis is to observe the effect of the lateral expansion on the pile capacity. Lateral expansion is a commonality among the three pile systems. In addition, BSAP and BRAP include other elements, such as steel bristles and lateral bolts, that penetrate the ground to provide additional shaft resistance. Thus, any improvement in load capacity shown by the FE results for the numerical model of BREP can be considered a lower bound for the other two systems. Even though the FE modeling examples shown herein consider axial pile compression only, it is anticipated that the proposed systems can also provide improved pullout capacity and this condition will be the focus of future research.

Greater advantages of the proposed deep foundation systems can be realised in granular soils that are not susceptible to liquefaction and are subjected to loading in axial compression or pullout mode in drained soil conditions. Corrosion protection (e.g., increase thick- 
ness of steel shell, epoxy coating) would be necessary if the site-specific conditions are those that would lead to steel corrosion in conventional piles. Effects of pile installation and expansion on the shaft resistance in clay soils and undrained conditions remain to be studied.

\section{Conclusion}

A multifaceted bioinspiration study was performed to generate design ideas for new deep foundations with greater load carrying capacity, particularly greater shaft resistance, compared to conventional cylindrical driven or bored piles. A problem-solving approach was used to define the problem and transfer strategies from the biology domain to geotechnical engineering. The bioinspiration considered the load transfer mechanism of hydroskeletons and the anchorage of the earthworm, razor clam, kelp, and lateral roots of plants. The concepts of three bioinspired deep foundation systems were suggested, incorporating biostrategies such as a flexible but incompressible core, a longitudinally split shell that allows expansion for anchorage, passive behaviour against external loading, and lateral root-type or setae-type anchoring elements. Lateral pile expansion is a common feature of the proposed systems. The advantage of this approach in terms of increased lateral confining pressure against the pile shaft and ultimate capacity compared to cylindrical piles in sand was illustrated with two FE modeling examples. The FE analyses also indicated that the increase in the lateral confining pressure at the end of pile expansion is maintained after pile loading. A detailed numerical parametric study and prototype testing of the laterally expansive deep foundation system are ongoing. Installation and material costs as well as sustainability assessment are important considerations in the development of the new foundations systems and will be addressed by subsequent research.

\section{Acknowledgment}

This material is based upon work primarily supported by the U. S. National Science Foundation (NSF) under NSF Award Number EEC-1449501. Any opinions, findings and conclusions, or recommendations expressed in this paper are those of the authors and do not necessarily reflect those of the NSF. The authors appreciate the advice of Dr. Dipanjan Basu in some aspects of the numerical modeling.

Open Access This article is licensed under a Creative Commons Attribution 4.0 International License, which permits use, sharing, adaptation, distribution and reproduction in any medium or format, as long as you give appropriate credit to the original author(s) and the source, provide a link to the Creative Commons licence, and indicate if changes were made.

The images or other third party material in this article are included in the article's Creative Commons licence, unless indicated otherwise in a credit line to the material. If material is not included in the article's Creative Commons licence and your intended use is not permitted by statutory regulation or exceeds the permitted use, you will need to obtain permission directly from the copyright holder.

To view a copy of this licence, visit http://creativecommons.org/licenses/by/4.0/.

\section{References}

[1] DeJong J, Burrall M, Wilson D W, Frost J D. A bio-inspired perspective for geotechnical engineering innovation. Proceedings of Geotechnical Frontiers 2017: Geotechnical Materials, Modeling, and Testing (GSP 280), Orlando, Florida, USA, 2017, 862-870.

[2] Benyus J. Biomimicry: Innovation Inspired by Nature, 1st ed., William Morrow \& Company Inc, New York, USA, 1997.

[3] Fayemi P E, Wanieck K, Zollfrank C, Maranzana N, Aoussat A. Biomimetics: Process, tools and practice. Bioinspiration \& Biomimetics, 2017, 12, 1-20.

[4] Enquist M, Linad J, Ghirlanda S. The power of associative learning and the ontogeny of optimal behaviour. Royal Society Open Science, 2016, 3, 1-25.

[5] Vincent J F V, Bogatyreva O A, Bogatyrev N R, Bowyer A, Pahl A K. Biomimetics: Its practice and theory. Journal of Royal Society Interface, 2006, 3, 471-482.

[6] Bogatyrev N R. A "living" machine. Journal of Bionic Engineering, 2004, 1, 79-87.

[7] Altshuller G, Shulyak L, Rodman S. The Innovation Algorithm: TRIZ, Systematic Innovation and Technical Creativity, 2nd ed., Technical Innovation Center, Worcester, USA, 2007.

[8] Vincent J F V, Mann D L. Systematic technology transfer from biology to engineering. Philosophical Transactions of the Royal Society A: Mathematical Physics and Engineering 
Sciences, 2002, 360, 159-173.

[9] Bogatyrev N, Bogatyreva O. TRIZ-based algorithm for biomimetic design. Procedia Engineering, 2015, 131, 377-387.

[10] Craig S, Harrison, D, Cripps A, Knott D. BioTRIZ suggests radiative cooling of buildings can be done passively by changing the structure of roof insulation to let longwave infrared pass. Journal of Bionic Engineering, 2008, 5, 55-66.

[11] Vincent J F V. Stealing ideas from nature. In Pellegrino S, eds., Deployable Structures, Springer, Vienna, 2000.

[12] $\mathrm{Hu}$ N, Feng P, Dai G. The gift from nature: Bio-inspired strategy for developing innovative bridges. Journal of Bionic Engineering, 2013, 10, 405-414.

[13] Grigorian M. Biomimicry and theory of structures-design methodology transfer from trees to moment frames. Journal of Bionic Engineering, 2014, 11, 638-648.

[14] Cortes D, John S. Earthworm-inspired soil penetration. Proceedings of the 1 st International Symposium of Bio-mediated and Bio-inspired Geotechnics, Atlanta, USA, 2018. (In press)

[15] Martinez A, DeJong J T, Jaeger R, Khosravi A. Evaluation of self-penetration potential of a bio-inspired site characterization probe by cavity expansion analysis. Canadian Geotechnical Journal, 2020, 57, 706-716.

[16] Huang S C, Tao J L. Modeling of the burrowing mechanism by razor clam: Role of penetration kinematics. Proceedings of IFCEE, ASCE, Orlando, USA, 2018, 547-556.

[17] Winter A G, Hosoi A E. Identification and evaluation of the Atlantic razor clam (Ensis directus) for biologically inspired subsea burrowing systems. Integrative and Comparative Biology, 2011, 51, 151-157.

[18] Winter A G, Deits R L H, Dorsch D S, Slocum A H, Hosoi A E. Razor clam to RoboClam: Burrowing drag reduction mechanisms and their robotic adaptation. Bioinspiration \& Biomimetics, 2014, 9, 1-11.

[19] Frost J D, Martinez A, Mallett S D, Roozbahani M M, DeJong J T. Intesection of modern soil mechanics with ants and roots. Proceedings of Geotechnical Frontiers 2017: Geotechnical Materials, Modeling, and Testing (GSP 280), Orlando, Florida, USA, 2017, 900-909.

[20] Alcantar J, Aleali A, Pasillas Rodriguez J N, Bandini P, Newtson C M. Bio-inspired vascular system in driven pile foundations. Proceedings of the 1st International Symposium of Bio-mediated and Bio-inspired Geotechnics, Atlanta, USA, 2018. ( In press)

[21] Hannigan P J, Rausche F, Likins G E, Robinson B R, Becker M L. Design and Construction of Driven Pile Foundations, technical report, National Highway Institute, FHWA GEC 012-volume I, USA, 2016.

[22] Randlolph M F, Dolwin R, Beck R. Design of driven piles in sand. Géotechnique, 1994, 44, 427-448.

[23] Kulhawy F H. Limiting tip and side resistance: Fact or fallacy? Analysis and Design of Pile Foundations, ASCE, New York, USA, 1984, 80-98.

[24] Recommended Practice for Planning, Designing and Construction Fixed Offshore Platforms - Load and Resistance Factor Design, 1997, API Recommended Practice 2A-LRFD (RP 2A-LRFD), 1st ed., American Petroleum Institute (API), Washington, DC, USA, reaffirmed 2003.

[25] Uesugi M, Kishida H. Frictional resistance at yield between dry sand and mild steel. Soils and Foundations, 1986, 26, 139-149.

[26] Frost J D, Martinez A. An axial-torsional multi-sleeve friction penetration system for lunar subsurface studies. Proceedings of the Earth and Space 2012 Conference, Pasadena, USA, 2012, 335-343.

[27] DeJong J T, Westgate Z J. Role of initial state, material properties, and confinement condition on local and global soil-structure interface behavior. Journal of Geotechnical and Geoenvironmental Engineering, 2009, 135, 1646-1660.

[28] Dietz M S, Lings M L. Postpeak strength of interfaces in a stress-dilatancy framework. Journal of Geotechnical and Geoenvironmental Engineering, 2006, 132, 1474-1484.

[29] Brown D A, Turner J P, Castelli R J. Drilled Shafts: Construction Procedures and LRFD Design Methods, National Highway Institute (FHWA GEC 010), USA, 2010.

[30] Edil T B, Bosscher P J, Sundberg A J. Soil-structure interface shear transfer behavior. Proceedings of the Second Japan-U.S. Workshop on Testing, Modeling, and Simulation (Geomechanics II) (GSP 156), Tokyo, Japan, 2005, 528-543.

[31] Iscimen M. Shearing Behavior of Curved Interfaces, $\mathrm{PhD}$ dissertation, School of Civil and Environmental Engineering, Georgia Institute of Technology, Atlanta, USA, 2004.

[32] Vogel S. Comparative Biomechanics: Life's Physical World, Princeton University Press, Princeton, USA, 2004, 580.

[33] Fitzgerald Marine Reserve. Kelp Holdfast, [2020-01-15], https://www.flickr.com/photos/131153742@N06/16947086 726/in/dateposted/ (Licensed under CC BY 2.0)

[34] Escobar A. Cross Section of a Tree's Roots, [2020-01-15], https://www.flickr.com/photos/aaronescobar/2569091622/ (Licensed under CC BY 2.0)

[35] Atwell B J. Response of roots to mechanical impedance. Environmental and Experimental Botany, 1993, 33, 27-40. 
[36] Kier W M. The diversity of hydrostatic skeletons. Journal of Experimental Biology, 2012, 215, 1247-1257.

[37] Wainwright S A. Axis and Circumference: The Cylindrical Shape of Plants and Animals, Harvard University Press, Cambridge, USA, 1988, 176.

[38] Cloudzilla. Stroke Stroke (Cat paw), [2020-01-15], https://www.flickr.com/photos/cloudzilla/391395459/ (Licensed under CC BY 2.0)

[39] Foreman T K, Linge K. The importance of heel compression in the measurement of diurnal stature variation. Applied Ergonomics, 1989, 20, 299-300.

[40] Ker R F. The design of soft collagenous load-bearing tissues. Journal of Experimental Biology, 1999, 202, 3315-3324.

[41] Wainwright S A, Biggs W D, Currey J D, Gosline J M.
Mechanical Design in Organisms, Princeton University Press, Princeton, USA, 1982, 423.

[42] Winter A G, Deits R L H, Hosoi A E. Localized fluidization burrowing mechanics of Ensis directus. Journal of Experimental Biology, 2012, 215, 2072-2080.

[43] Abaqus 2017 Analysis User's Manual, Dassault Systèmes Simulia Corp, Providence, USA.

[44] Been K, Jefferies M G, Hachey J E. The critical state of sands. Géotechnique, 1991, 41, 365-381.

[45] Jefferies M G. Nor-Sand: A simple critical state model for sand. Géotechnique, 1993, 43, 91-103.

[46] Yu H. Plasticity and Geotechnics, Springer, New York, USA, 2006. 